$$
\begin{array}{r}
\text { Húmus, } \\
\text { de Raul Brandão, } \\
\text { enc. Luis Castro, } \\
\text { Karnart } 2010 \\
\text { (André Uerba), } \\
\text { fot. Patrícia Rego. }
\end{array}
$$

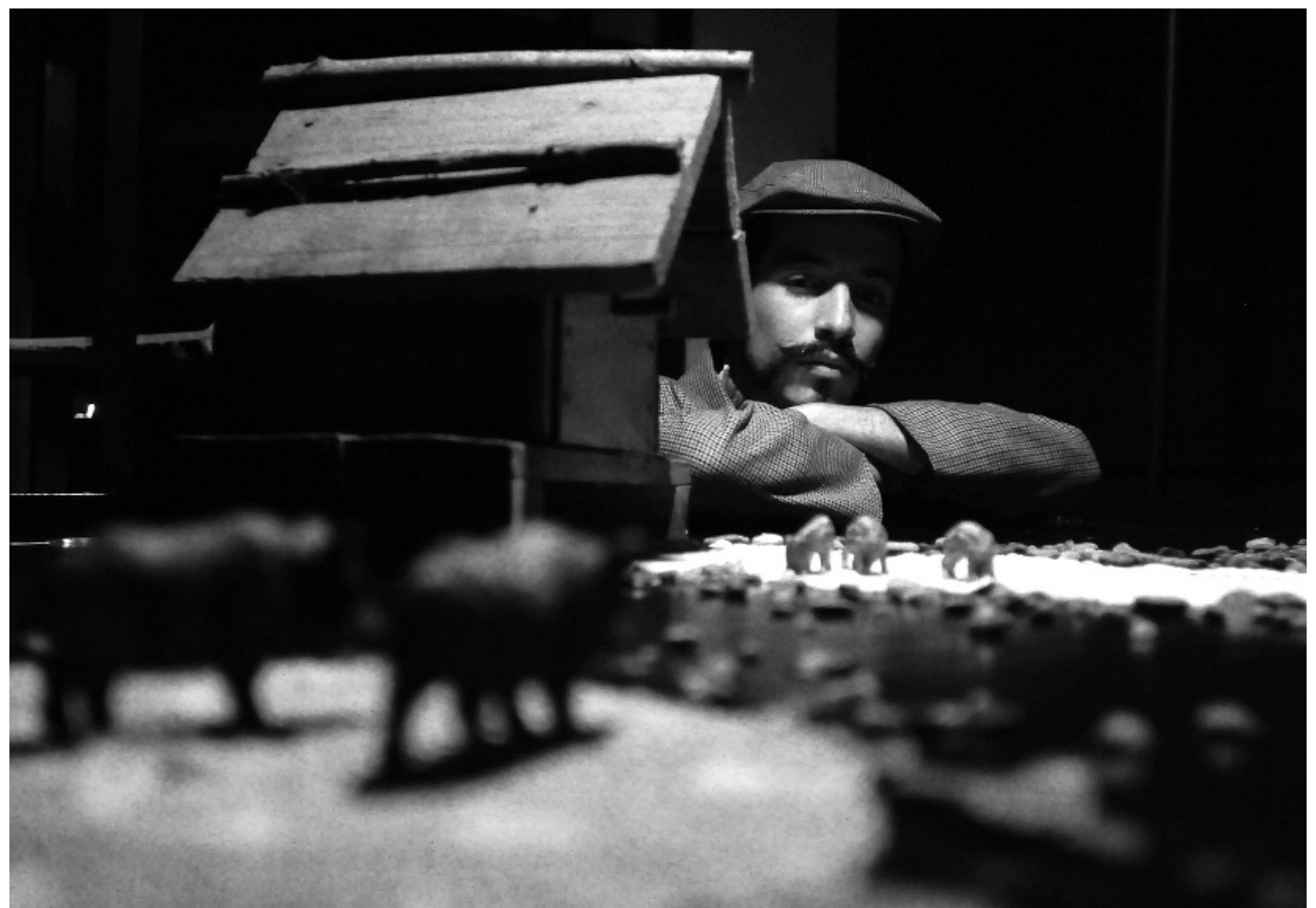

\title{
Evocar em perfinst a dor dos deserdados
}

\author{
Maria Helena Serôdio
}

0 júri do Prémio da Crítica (da Associação Portuguesa de Críticos de Teatro) declarava na sua nota para a imprensa que a Menção Especial que atribuia a Luis Castro / Karnart se devia à inspirada e brilhante teatralização do universo de Raul Brandão no espectáculo Húmus, afeiçoando a estética da perfinst a uma evocação compadecida dos humildes que habitam a obra de Raul Brandão.

Usando de forma criativa os vários espaços da Galeria Monumental (em Lisboa, no Campo Mártires da Pátria), Luís Castro concebeu - com a assistência plástica de Vel $\mathrm{Z}$ e a banda sonora de Adriano Filipe - um percurso de acções que os actores/performers André Uerba, Bibi Perestrelo, Fernando Grilo, Mariana Lemos, Sara Carinhas e Vel Z iam executando de forma rigorosa e ordenada, mas paredes meias com a evocação do onírico, esconjurando, assim, fantasia e dor, desejo e medo, vida e morte.

Partindo de três textos de Raul Brandão - Húmus (1917), História dum palhaço: A vida e o diário de K. Maurício (1896) e A morte do palhaço (1926) - o espectáculo estava escandido em várias partes e cada cena decorria em lugares diferentes da Galeria: Sala 1, Sala 2, Sala do fundo, Galeria, Pátio, Sala Preta. 0 que isso sinalizava era não apenas a possibilidade de criar diferentes atmosferas nos enquadramentos que a arquitectura permitia e a iluminação modalizava, mas também a deambulação que se oferecia

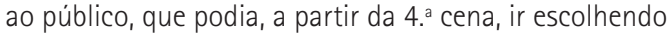

a acção a que quereria assistir, podendo a qualquer altura passar de um lugar para outro.

A narrativa poética de assombração e piedade, que marca a obra de Raul Brandão, era dita, na maior parte do espectáculo, em voz off, e o espectáculo, no seu conjunto, apresentava-se numa hábil sobreposição entre essa palavra dita e as acções que os actores cumpriam manipulando objectos em vários lugares da Galeria, o que torna possivel não apenas referir o espectáculo a uma "especificidade do lugar" (site specificity), daquele lugar concreto, mas reconhecer nele também uma outra forma de apresentação e valoração do trabalho dos actores.

Nesse último sentido poderíamos invocar os conceitos que Erika Fischer-Lichte usou ${ }^{1}$ para distinguir o funcionamento do corpo do actor em cena: "corpo semiológico", quando o actor "encarna" uma personagem ("sinalizando" uma outra realidade para que remete), e o "corpo fenomenológico", quando a presença do actor se reporta a uma estética que sublinha a importância do corpo físico do actor como elemento que vale por si e não como representando um outro corpo ou uma personagem.

Poder-se-ia argumentar que, pelo menos, são duas as personagens que no espectáculo são referidas às figuras concretas das actrizes: D. Restituta (da 1. ${ }^{a}$ cena) e Teodora. Mas um outro elemento do espectáculo ajuda a manter separada esta sobreposição: as actrizes não falam nestes dois casos, e é o "narrador" que as apresenta, de forma 

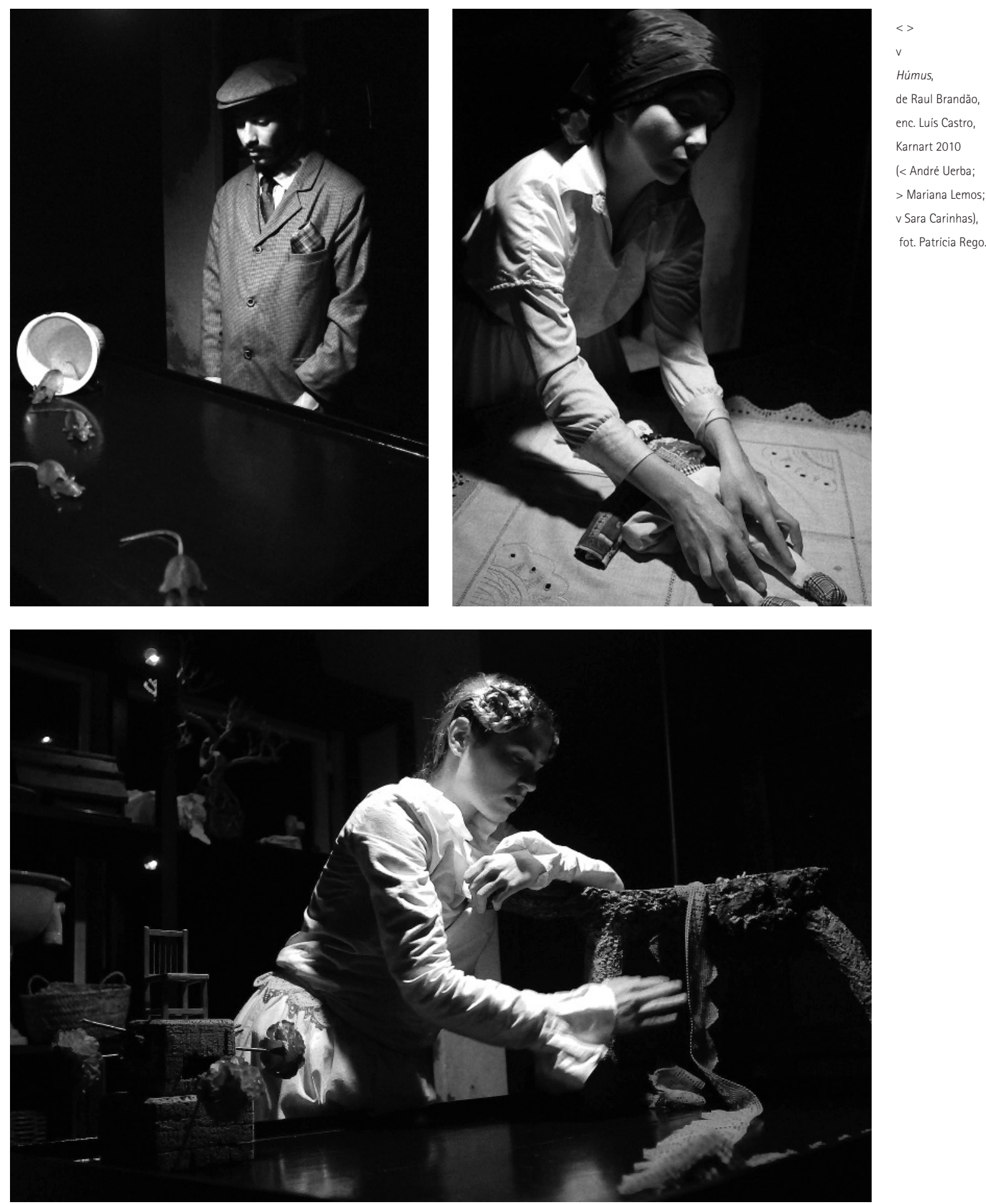

compadecida, como é, aliás, a voz que acompanha os actores (e o público) em quase todo o "processo" do espectáculo.

Essa voz off(a de Luís Castro) ia dizendo o texto de forma pausada e clara, visando uma modulação relativamente neutra, evitando, assim, uma leitura de eventual - indignação arrebatada ou piedosa lamúria. Mantinha, por isso, para o espectador, uma atenção disponivel, mas não orientada, o que se reforçava ainda com a partitura sonora (num excelente arranjo de Adriano Filipe) que, de um modo geral, evocava música sacra e criava uma atmosfera de recolhimento e melancolia.
Apenas num caso - na narrativa do amor - era consentida a voz da actriz Sara Carinhas, que a dizia em cena, repartindo-se entre a razão do palhaço e a loucura apaixonada do clown. Mas, também aqui, texto e figuração pareciam "confrontar-se", não só porque eram duas as figuras evocadas por uma só actriz, mas também porque se jogava com a dualidade: por debaixo da longa capa preta surgia a roupa vermelha da actriz e, uma vez sentada de frente para o público, jogava com as mãos, erguidas à altura da cara, e que tanto podiam recordar duas possiveis marionetas, como figuras aladas que pareciam dialogar/discutir entre si. 

Húmus,
de Raul Brandão,
enc. Luis Castro,
Karnart 2010
(Sara Carinhas),
fot. Patricia Rego.

然

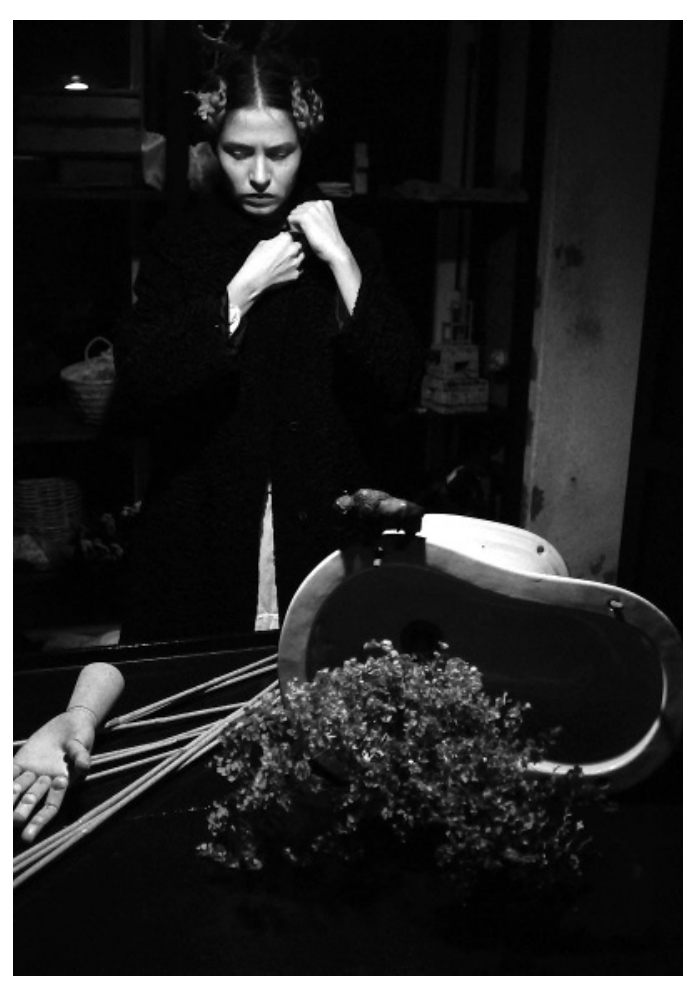

0 espectáculo não visava, de facto, "ilustrar" o texto dito, mas antes, de forma rugosa e inesperada, apontar para acções e quadros, de recorte humano, e que, ao lado do texto, iam criando focos de atenção e justificando o percurso que o público escolhia fazer.

E se as cenas iniciais na Sala 1 (com mãe e filho) e Sala 2 (na cena do palhaço e clown) se ofereciam como foco único de atenção, a galeria e a sala do fundo instalavam no espectáculo o lugar da deambulação, embora oferecendo-se em contraste claro. Com efeito, na sala ao fundo podia identificar-se, de forma naturalista, o interior de uma casa rústica, com a cozinha - onde não faltavam utensilios reconheciveis e mesmo um forno para fazer pãezinhos - e a evocação, pela cama de ferro, de um quarto onde se deita a "Majestosa Teodora".

De forma diferente, a galeria instalava três mesas onde Mariana Lemos, Sara Carinhas e André Uerba iam montando e desmontando instalações a partir de objectos que se diferenciavam, entre si, pelo material de que eram feitos, bem como pelas dimensões e sentido simbólico. De facto, panejamentos, bibelots, bonecas, toalhas, animais de plástico, naperons, até mesmo uma arrastadeira, etc. serviam as acções em que os performers trabalhavam com uma dedicação e espessura de gestos de grande expressividade.

Algumas das opções de enquadramento revelavam uma inteligente apropriação do lugar, de forma simples e sem imposição de sentidos, mas, ao mesmo tempo, criando o espaço para possíveis leituras, imaginação à solta a completar esse "espanto aos gritos" que é o lugar da fala e a raiz do sentimento de Raul Brandão. Foi o caso, por exemplo, da colocação da segunda cena no vão da janela / montra que dava para a rua: larga e alta e com parapeito à altura do joelho, oferecia-se como um possivel altar lateral de uma igreja, mas onde a parede acolhedora deste era substituida pelo vidro que deixava ver o movimento de pessoas e carros na rua, a "realidade" que se torna a medida daquela renúncia. Uma mãe, cujo "nome" traz a marca de uma tragédia grotesca - Restituta da Piedade Sardinha -, surge como uma possivel inversão de uma mater dolorosa de um jovem que, embora criado a esmolas e côdea, subiu na vida e agora, prestes a casar rico, quer simplesmente que a mãe desapareça para que nada prejudique a sua imagem social.

Se quisermos procurar o lugar ideológico da voz que fala - a que Raul Brandão criou nesta obra em particular, mas que atravessa grande parte dos seus escritos -, teremos de juntar as razões do anarquismo (de sentido proudhoniano) a uma autêntica piedade cristã para com os humildes e ofendidos, bem longe da oligarquia mandante e dos rituais faustosos católicos; e ligar o horror pela violência e pela injustiça a uma meditação sofrida sobre a vida, o sonho, a morte. E esse é um legado político, cultural e artístico que resultou bem claro nesta produção do Karnart.

Preconizava Brandão, nos seus escritos, um teatro "simples e cavado fundo no coração humano", que nos fizesse sonhar ou pensar e onde se deveria discutir "um grande problema, psicológico ou social, mas sem frases: vendaval que arraste os espectadores [...] actos seguidos como uma faca que se enterra" (Brandão 1986: 173).

$E_{1}$ ao recordar neste Húmus a denúncia do sofrimento infligido pela sociedade aos mais humildes, a obra de Raul Brandão desdobra-se numa mistura de sagrado e desprezivel, de choro e revolta, de real degradado e fiapos de sonho, e que ganharam forma e som neste espectáculo de perfinst do Karnart que, com a direcção de Luis Castro e as colaborações artísticas com que pôde contar, marcou o teatro português em 2010 e por isso bem mereceu a Menção Especial que a APCT Ihe atribuiu.

\section{Referência bibliográfica}

BRANDÃO, Raul (1986), Teatro, Lisboa, Comunicação. 